\title{
Multicontrast 3D automated segmentation of cardiovascular images
}

\author{
Matthew Bramlet ${ }^{1 *}$, Anthony G Christodoulou ${ }^{2,3}$, Brad Sutton ${ }^{2,3}$ \\ From 19th Annual SCMR Scientific Sessions \\ Los Angeles, CA, USA. 27-30 January 2016
}

\section{Background}

Our work explores the use of multiple contrasts to perform automated 3D cardiovascular image segmentation, with the goal of facilitating 3D assessment of subjectspecific heart models.

The signal intensity of MR images is a function of intrinsic tissue parameters (e.g., spin density $\rho, T_{1}$, and $T_{2}$ ), and chosen sequence parameters (e.g., flip angle, $\left.T_{\mathrm{R}}, T_{\mathrm{I}}\right)$. MR images do not directly measure the underlying states of the tissue parameters, but rather provide observations of functions of the underlying states. When sequence parameters are selected properly, the contrast between tissue types is high enough to allow differentation of tissues via image segmentation.

Our work explores image segmentation using multiple image contrasts (i.e., multiple acquisitions using different sequence parameters). With multiple contrasts, the signal intensities from different images can be used to form a multidimensional feature space, increasing the distance between observations of different tissues as compared to a one-dimensional feature space based on a single image contrast.

\section{Methods}

We simulated the signal intensity of each tissue for an IR-bSSFP pulse sequence at $1.5 \mathrm{~T}$ using common tissue parameters where air was assumed to have zero signal in addition to the following sequence parameters: flip angle $=$ $65^{\circ}, T_{\mathrm{R}}=4 \mathrm{~ms}$, and a range of inversion times from $48 \mathrm{~ms}$ to $540 \mathrm{~ms}$. Figure 1 illustrates the advantage of using multiple contrasts for separating tissues, depicting the signal intensities and example separation boundaries between

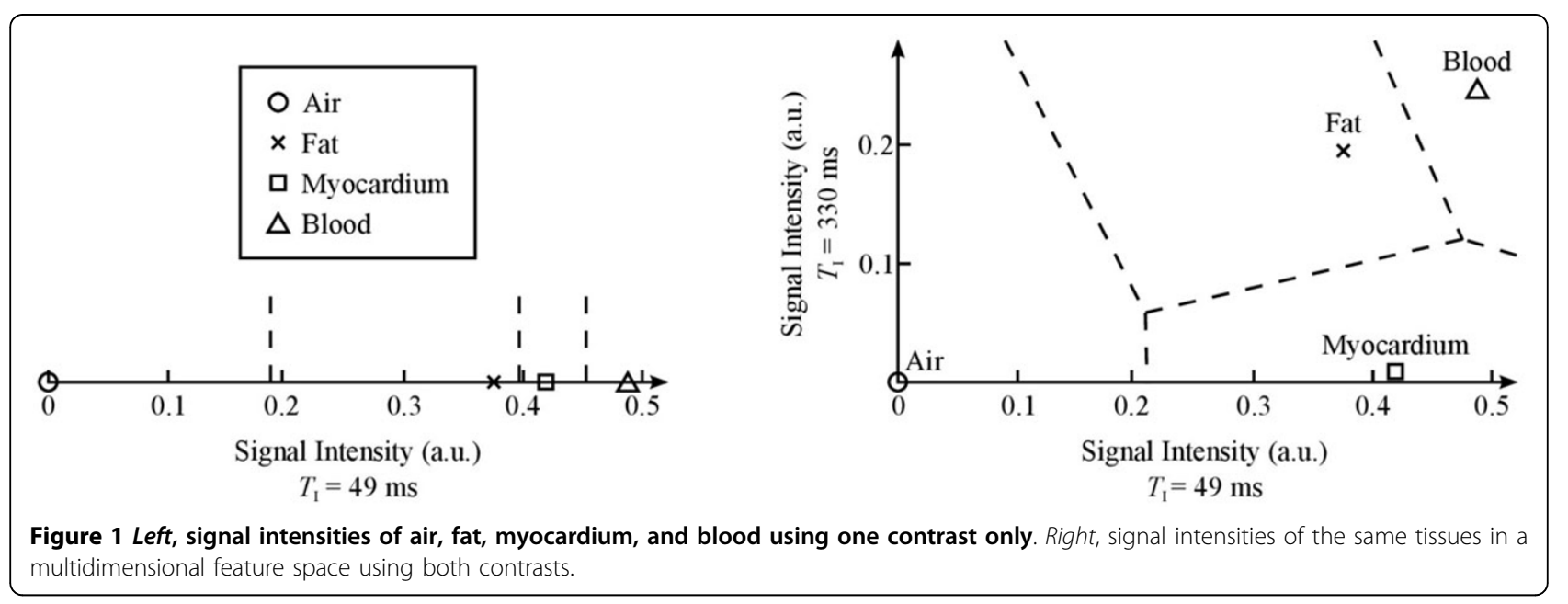

'Pediatric Cardiology, Children's Hospital of Illinois, University of Illinois

College of Medicine at Peoria, Peoria, IL, USA

Full list of author information is available at the end of the article 


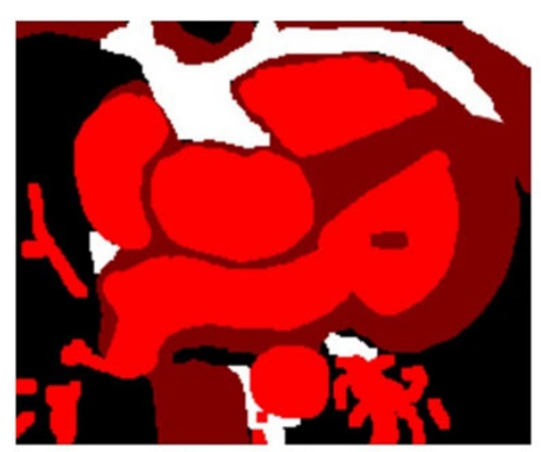

Manually drawn

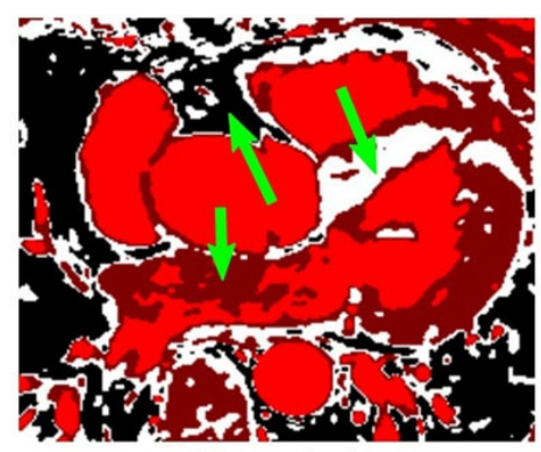

One contrast

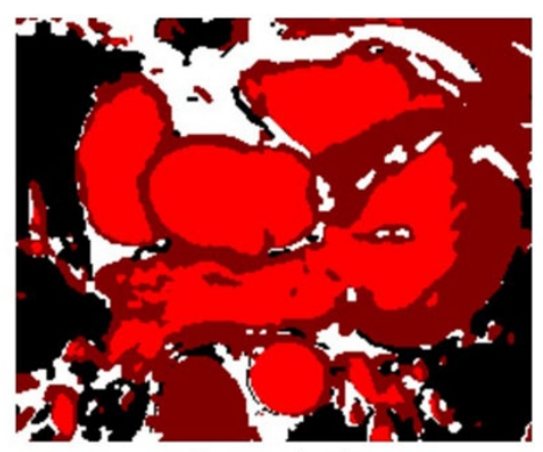

Two contrasts

Figure 2 Left, manual segmentation of tissues (for reference). Center, FAST with one image contrast. Right, FAST with two image contrasts. Arrows indicate large areas of error when using only one image contrast.

tissues for: left, a single contrast, using $T_{\mathrm{I}}=49 \mathrm{~ms}$; and right, two contrasts, using $T_{\mathrm{I}}=49 \mathrm{~ms}$ and $T_{\mathrm{I}}=330 \mathrm{~ms}$.

\section{Results}

A proof of concept 3D IR-bSSFP scan was collected with different inversion times; all other parameters were the same for both scans using $T_{\mathrm{I}}=49 \mathrm{~ms}$ and $T_{\mathrm{I}}=330$ ms. Images were processed using the FMRIB Software Library (FSL). Images were registered with the FLIRT tool, employing mutual information as the similarity metric, then cropped to include only the heart. The cropped, registered images were segmented by inputting both contrasts into the FAST tool. The number of tissues was specified as four, with the intent of differentiating air, fat, blood, and myocardium.

Figure 2 shows segmentation results using: left, manual drawing (for reference); center, FAST with one image contrast $\left(T_{\mathrm{I}}=49 \mathrm{~ms}\right)$; and right, FAST with both image contrasts $\left(T_{\mathrm{I}}=49 \mathrm{~ms}\right.$ and $\left.T_{\mathrm{I}}=330 \mathrm{~ms}\right)$. Using only one contrast results in large areas of tissue misclassification, as indicated by the arrows. The use of multiple image contrasts results in vastly improved tissue classification.

\section{Conclusions}

As more advanced $3 \mathrm{D}$ viewing tools become available, the need to automate the segmentation process grows. This simple technique demonstrates a shift in imaging goal from high resolution $2 \mathrm{D}$ acquisition to tissue identification and lays the foundation for future sequence design.

\section{Authors' details}

${ }^{1}$ Pediatric Cardiology, Children's Hospital of Illinois, University of Illinois College of Medicine at Peoria, Peoria, IL, USA. ${ }^{2}$ Bioengineering, University of Illinois College of Engineering, Urbana, IL, USA. ${ }^{3}$ Beckman Institute for Advanced Science and Technology, University of Illinois, Urbana, IL, USA.

Published: 27 January 2016
doi:10.1186/1532-429X-18-S1-0114

Cite this article as: Bramlet et al: Multicontrast 3D automated segmentation of cardiovascular images. Journal of Cardiovascular Magnetic Resonance 2016 18(Suppl 1):0114.
Submit your next manuscript to BioMed Central and take full advantage of:

- Convenient online submission

- Thorough peer review

- No space constraints or color figure charges

- Immediate publication on acceptance

- Inclusion in PubMed, CAS, Scopus and Google Scholar

- Research which is freely available for redistribution
Biomed Central 